\title{
Mémoire épique et Génie du lieu, études réunies par Caroline CAZANAVE
}

\author{
Maria Colombo Timelli
}

\section{OpenEdition}

\section{Journals}

\section{Édition électronique}

URL : http://journals.openedition.org/studifrancesi/16146

DOI : 10.4000/studifrancesi. 16146

ISSN : 2427-5856

\section{Éditeur}

Rosenberg \& Sellier

\section{Édition imprimée}

Date de publication : 1 juillet 2019

Pagination : 131-132

ISSN : 0039-2944

\section{Référence électronique}

Maria Colombo Timelli, « Mémoire épique et Génie du lieu, études réunies par Caroline cazanave », Studi Francesi [En ligne], 187 (LXIII | I) | 2019, mis en ligne le 01 juillet 2019, consulté le 24 janvier 2021. URL http://journals.openedition.org/studifrancesi/16146 ; DOI : https://doi.org/10.4000/studifrancesi. 16146

Ce document a été généré automatiquement le 24 janvier 2021.

\section{(c)}

Studi Francesi è distribuita con Licenza Creative Commons Attribuzione - Non commerciale - Non opere derivate 4.0 Internazionale. 


\title{
Mémoire épique et Génie du lieu, études réunies par Caroline
}

\section{CAZANAVE}

\author{
Maria Colombo Timelli
}

\section{RÉFÉRENCE}

Mémoire épique et Génie du lieu, études réunies par Caroline CAZANAVE, Lille, Centre d'études médiévales et dialectales de Lille 3, «Bien Dire et Bien Aprandre», hors-série 2, 2017, 379 pp.

1 Consacré à la transmission du patrimoine épique français sur la longue diachronie, ce recueil se compose de deux parties. La première, entièrement rédigée par Caroline CAZANAVE, met l'accent sur les différents processus auxquels la matière originale a été soumise lors de ses multiples réécritures: sur le plan littéraire, variations thématiques et insertion de motifs d'origine diverse et variée ont produit une hybridation générique qui a garanti la survie du fond médiéval; mais la transmission s'est faite aussi par l'ouverture à d'autres médias: théâtre, musique, chant, danse, cinéma, voire BD, ont accompli une réception tout aussi significative qui a atteint les publics les plus vastes. Par ailleurs, les gestes les plus fortunées - de Roland à Fierabras, de Guillaume aux Quatre fils Aymon - montrent combien la perception actuelle du Moyen Âge épique dépend davantage de cette réception que des textes fondateurs. On soulignera aussi que le parcours proposé par C.C., couvrant du $\mathrm{XII}^{\mathrm{e}}$ au $\mathrm{xx}^{\mathrm{e}}$ siècle, n'hésite pas à traverser les frontières tant géographiques que linguistiques (Délocalisastions et reformulations de l'épique médiéval, pp. 9-135).

2 La seconde partie, Illustrer le génie du lieu épique, réunit une dizaine de contributions consacrées chacune à une "pérégrination», dans le temps et dans l'espace, de la matière épique médiévale. 
3 Si le titre de Chanson de Roland est inconnu à la tradition manuscrite, il est si profondément rattaché au poème de Turold qu'il vaut la peine d'en parcourir la genèse. C'est le propos de Christopher LUCKEN, qui souligne premièrement les apports des érudits $d u$ XVIII $^{\mathrm{e}}$ siècle, basés sur la légende d'un Taillefer «chantant» pendant la bataille de Hastings, puis des savants $\mathrm{du} \mathrm{XIX}^{\mathrm{e}}$ siècle, avant et après la découverte du manuscrit d'Oxford. Celle-ci semble être venue justement combler l'attente d'une «chanson», dont le rapport avec les cantilenae célébrant Roncevaux fut développé et discuté notamment par G. Paris et L. Gautier (De la «chanson» de Roland au manuscrit d'Oxford. En quête du chant primitif, pp. 141-164).

4 La geste de Renaut de Montauban, qui a connu une fortune ininterrompue dans l'Europe entière du Moyen Âge à nos jours, fait l'objet de l'article de Sarah BAUDELLEMICHELS; elle y montre les diverses appropriations de la légende en Gascogne, dans les Flandres, en Wallonie, dans les Ardennes: ce désir d'ancrer les Quatre Frères à des lieux bien réels va pourtant à l'encontre des textes médiévaux, dont les protagonistes ne revendiquent de fait aucune appartenance géographique (Les appropriations géographiques des quatre fils Aymon, pp. 165-176).

5 Hélène GaLlé lit en parallèle les versions du Departement des enfanz Aymeri, épisode charnière entre le cycle de Narbonne et celui de Guillaume, remanié et adapté en vers et en prose entre le $\mathrm{XIII}^{\mathrm{e}}$ et le $\mathrm{XV}^{\mathrm{e}}$ siècle. Elle classe les principales modifications introduites en particulier dans le Roman de Guillaume d'Orange autour de trois verbes: «compresser» (l'auteur resserre la trame tout en multipliant les renvois internes), «polir» (il augmente sensiblement la dimension courtoise, en adoucissant les caractères masculins et en multipliant les présences féminines), "assagir» (il supprime la démesure épique originale des personnages au profit de la modération et de la courtoisie) («Le Departement des enfanz Aymeri» ou «L'inévitable loy du tems et du destin textuels», pp. 179-205).

6 L'histoire de Theseus de Cologne a connu, elle aussi, de nombreuses versions sous des formes et dans des genres différents. Mari BACQUIN en rappelle les étapes principales: la chanson $\mathrm{du} \mathrm{XIV}^{\mathrm{e}}$ siècle fut bientôt suivie d'un «miracle», joué en 1374, puis, au siècle suivant, de deux «mises en prose»: l'une rédigée pour rattacher la famille des Dammartin à un des protagonistes, Assaillant; l'autre, de Jean Servion, pour célébrer, à travers une généalogie fantaisiste, la maison de Savoie. Deux éditions $d u \mathrm{XVI}^{\mathrm{e}}$ siècle (Antoine Bonnemère, 1534, et Jean Bonfons, s.d.), transmettent quant à elles une adaptation en prose assez fidèle aux vers. Une dernière réception est représentée par l'extrait paru dans les Mélanges tirés d'une grande bibliothèque du marquis de Paulmy en 1781. Ce succès prolongé permet de mesurer non seulement l'intérêt que la matière a suscité à diverses époques, mais surtout sa capacité à s'adapter aux buts de chaque auteur (Pérégrinations d'un récit: l'exemple de «Theseus de Cologne», pp. 207-220).

7 L'épopée française a connu également une réception italienne. Jean-Claude VALLECALLE s'attache à Aquilon de Bavière, adapté au monde des signorie par Raffaele da Verona, au tournant $\mathrm{du} \mathrm{XIV}^{\mathrm{e}}$ et $\mathrm{du} \mathrm{XV}^{\mathrm{e}}$ siècle: situé dans la continuité des gestes de France, son œuvre n'en constitue pas moins à la fois une synthèse aux prétentions historiques et une profonde réécriture au moment même où la tradition épique franco-italienne s'éteint («Aquilon de Bavière» ou la réinvention de la mémoire, pp. 221-232).

8 Les derniers articles portent sur des réceptions beaucoup plus éloignées dans l'espace et dans le temps. Il est question tour à tour de l'œuvre d'un écrivain tchèque du XVIII ${ }^{\mathrm{e}}$ 
siècle (Miroslava NovotNÁ, Le «Couronnement du roi Louis» de Julius Zeyer, pp. 236-247), des récits de la littérature de cordel brésilienne (Martine KUNZ, La geste de Charlemagne ou l'histoire métissée d'un texte à plusieurs voix, pp. 249-260), du répertoire des marionnettes de Liège (Marc LE PERSON, «Fierabras» dans le théâtre des marionnettes liégeoises, pp. 263-287; Caroline CAZANAVE, Le "Milles et Amys» de Jean-Claude Maggi. La réception théâtrale à Liège d'une légende incroyablement remaniée, pp. 289-317), et enfin des représentations d'un théâtre indien (Gilles TARABOUT, Charlemagne en pays malabar. Enjeux locaux, pp. 317-329). Les Annexes proposent trois des pièces de marionnettes commentées: Fier-à-Bras anonyme, Fierabras le Terrible de Jean-Claude Maggi, Milles et Amys du même auteur. 